\title{
A metacognição de usuários no processo de busca da informação em catálogo coletivo de biblioteca universitária
}

Paula Regina Dal' Evedove

Professora Adjunta do Departamento de Ciência da Informação da Universidade Federal de Pernambuco/UFPE. Doutora em Ciência da Informação pela Faculdade de Filosofia e Ciências da Universidade Estadual Paulista "Júlio de Mesquita Filho", Tecnóloga em Gestão de Pessoas pelo Centro Universitário Eurípides de Marília/UNIVEM.

Dulce Amélia de Brito Neves

Professora Associada do Departamento de Ciência da Informação da Universidade Federal da Paraíba/UFPB. Bacharel em Biblioteconomia pela Universidade Federal da Paraíba, mestrado em Biblioteconomia pela Universidade Federal da Paraíba, doutorado em Ciências da Informação pela Universidade Federal de Minas Gerais, Pósdoutorado pela Faculdade de Letras da Universidade do Porto. Professora do Departamento de Ciência da Informação da Universidade Federal da Paraíba.

Mariângela Spotti Lopes Fujita

Professora Titular do Departamento de Ciência da Informação da Universidade Estadual Paulista/UNESP.Doutorado em Ciências da Comunicação pela Universidade de São Paulo Titular em Leitura Documentária e Indexação Titular do Departamento de Ciência da Informação da UNESP. Pró-Reitora de Extensão Universitária na UNESP.

http://dx.doi.org/10.1590/1981-5344/1794

Observou-se a trajetória metacognitiva de usuários de uma biblioteca universitária a fim de identificar as estratégias metacognitivas utilizadas durante o processo de busca da informação em catálogo coletivo online. Sua configuração foi pautada nos relatos orais dos sujeitos participantes obtidos por meio da técnica do Protocolo Verbal Individual de modo a propiciar uma configuração 
real da tarefa e uma análise mais aproximada do seu fazer natural em sistemas de recuperação da informação. Os resultados demonstram que o conhecimento de estratégias metacognitivas repercute na qualidade dos resultados obtidos no processo de busca da informação e interferem no modo como se concretiza a recuperação da informação em catálogo online, fato que acentua a necessidade de estudos que avancem em questões relacionadas à metacognição de usuários de informação.

Palavras-chave: Metacognição; Comportamento informacional; Processo de busca da informação; Usuário de informação; Biblioteca universitária.

\section{The metacognition of users in the process of information search in collective catalogs of university library}

It was observed the metacognitive trajectory of three users from a public university library the state of Sao Paulo to identify the metacognitive strategies that were used during the process of searching for information in a online collective catalog. Its configuration was based on participants 'oral reports obtained by the technique of individual verbal protocol to provide an actual configuration of the task ans a closer examination of its natural recovery of information systems. The data collection sessions were recorded, and the recorded data were transcribed and categorized into four units of analyses: 1- expertise, 2-regulation, 3-assessment of knowledge itself and 4- organization of cognitive process. The results showed that knowledge of meta-cognitive strategies affects the quality of the results obtained in the process of searching for information and interferes in the way it implements retrieval on-line catalog, a fact the emphasizes the need for studies to move forward on issues meta-cognition of users of information.

Keywords: Metacognition; Information behavior; Process of information search; User information; University library.

Recebido em 29.04.2013 Aceito em 29.09.2014 


\section{Introdução}

Uma das ambições em termos investigativos da Ciência da Informação é retirar o fosso entre o usuário e o sistema de informação, a fim de estreitar o relacionamento entre os atores sociais que atuam no processo de organização e recuperação da informação. Diante do desafio supramencionado e do postulado de que a recuperação da informação deve propiciar resultados condizentes com as necessidades dos usuários, nos últimos anos a área de comportamento informacional ganha destaque perante à comunidade científica ao identificar os fatores que geram as necessidades de informação nos usuários; as etapas do processo de busca; quais elementos influenciam este comportamento; e para que fim essas informações são utilizadas (BARRETT, 2005). Como resultado prático, tem-se a obtenção de subsídios reais para o planejamento de produtos e serviços mais ajustados à comunidade usuária.

Bates (1996) alerta que ao estarem desprovidos de uma investigação científica, os modos de organização e acesso à informação no contexto de bibliotecas passam a suprir de maneira superficial as necessidades informacionais dos usuários, acarretando em sistemas de informação deficitários. Relativo aos sistemas de informação, Varela; Barbosa (2012) assinalam que os artefatos de informação - representados nesta pesquisa pelo catálogo online de biblioteca universitária - estão em mudanças constantes, principalmente no que tange aos modelos de comunicação, a exemplo da plataforma web 2.0. Diante desta realidade, as bibliotecas adotam uma linha de gestão em que toda e qualquer atitude assumida toma como ponto de partida as necessidades $e$ expectativas da comunidade usuária.

Diante do exposto, a intenção deste estudo é avançar no escopo investigativo da área de comportamento informacional e considerar, além dos aspectos cognitivos, as estratégias metacognitivas de usuários no processo de busca da informação. Portanto, aproximam-se dois temas atuantes em Ciência da Informação, porém difusos em termos de intersecção investigativa - metacognição e usuário da informação. 0 desafio central é refletir sobre o conhecimento metacognitivo e sua relevância para os estudos em Ciência da Informação relacionados ao comportamento humano frente à informação, especificamente no que tange ao usuário no processo de busca em sistemas de recuperação da informação.

Parte-se da prerrogativa de que ao ter controle metacognitivo de estratégias aplicadas na busca da informação (habilidades de localizar e recuperar documentos), o usuário tende a realizar o processo de modo mais dinâmico e eficaz em virtude da capacidade de compreensão e monitoramento de seus próprios processos cognitivos. Entende-se que abordar a questão da estratégia de busca e os aspectos que envolvem esse processo na perspectiva da metacognição é uma possibilidade alternativa para verificar se os resultados alcançados na recuperação da 
informação são condizentes com as necessidades investigativas dos usuários.

Neste sentido, acredita-se que o conhecimento das estratégias metacognitivas utilizadas pelo usuário para sanar uma necessidade de informação defronte a busca em catálogos online pode propiciar subsídios relevantes para o aprimoramento dos produtos e serviços oferecidos pelas bibliotecas universitárias. Isto porque, os catálogos online são constituídos por três componentes básicos: 1) indexação; 2) armazenamento; e 3) recuperação da informação (ROWLEY, 2002), sendo que a indexação ou catalogação por assuntos requer conhecimentos contextuais relativos, dentre outros, ao comportamento informacional dos usuários (FUJITA; AUGUSTÍN LACRUZ; GÓMEZ DÍAS, 2011). Este fator acentua a importância do estudo de usuário como contributo para a qualidade dos catálogos coletivos na condição de "instrumentos plurifuncionais" disponíveis na web (FUJITA, 2009a). Além disso, identifica-se na literatura especializada uma carência de estudos sobre a metacognição de usuários, isto é, pesquisas que considerem a trajetória metacognitiva traçada pelos usuários na recuperação da informação em catálogos coletivos online de bibliotecas universitárias e na perspectiva do comportamento informacional.

Sendo assim, a primeira parte do estudo apresenta uma interlocução teórica entre a área do comportamento informacional e a psicologia de processamento da informação, mais precisamente as reflexões relativas à metacognição. Posteriormente, observa-se o comportamento informacional de usuários no uso do catálogo coletivo online de biblioteca universitária, objetivando-se identificar as estratégias metacognitivas utilizadas durante o processo de busca e recuperação da informação. Para tanto, o estudo abrange três discentes de graduação de uma universidade pública nacional. Sua configuração está pautada nos relatos orais (protocolo verbal) dos sujeitos participantes, de modo a propiciar uma configuração real do processo de busca da informação e uma análise mais aproximada do seu fazer natural em sistemas de recuperação da informação de domínios específicos.

\section{Comportamento informacional}

A necessidade de informação é resultante da condição do conhecimento como fator desencadeante do desenvolvimento humano. Nesta perspectiva, muitas são as razões que levam o sujeito buscar informação significativa, aclamada durante o processo de conhecimento, quais sejam: preencher uma lacuna apresentada em uma dada situação; bem-estar social; ampliar seus conhecimentos sobre determinado problema ou assunto; obter desenvolvimento social, político ou econômico; dentre outros. Em especial, as diferentes necessidades de informação são motivadas pela crescente diversidade de mudanças no mundo contemporâneo, o qual assiste a um período de grandes transformações. Tais necessidades de informação são desencadeadas em 
situações e experiências específicas, pois não se pode pretender conhecer o todo simplesmente porque, na condição de seres humanos, possuímos uma capacidade cognitiva limitada, o que nos obriga a refinar a informação para sanar determinadas incertezas em situações específicas (VARELA; BARBOSA, 2012).

Do ponto de vista objetivo, a necessidade básica do ser humano respalda-se na busca incansável por novas informações que sanem o seu estado de anomalia, resultante de uma deficiência em seu estado de conhecimento (LE COADIC, 1996). Consciente de tal necessidade, o sujeito se projeta na busca pela informação para alterar o seu estado de conhecimento, em que a informação move o sujeito de um estado prévio de conhecimento para um novo estado por meio de suas habilidades cognitivas (BELKIN; ROBERTSON, 1976). A produção de um novo conhecimento dá-se no momento em que uma dada informação, desconhecida até o momento, é incorporada e modifica os estados cognitivos do sujeito, resultando no novo conhecimento. Em outras palavras,

a produção ou geração de conhecimento é uma reconstrução das estruturas cognitivas, ou seja, uma modificação em seu estoque mental de saber acumulado, resultante de uma interação com uma informação percebida e aceita (BARRETO, 2003, p.58).

A necessidade de mudança do seu estado de conhecimento gera o comportamento de busca e uso da informação ou comportamento informacional. Trata-se dos métodos e ações empreendidas pelos sujeitos na obtenção de informações para satisfazer suas necessidades informacionais (CALVA GONZÁLES, 2004). Esta configuração denominada de "alternativa" dos estudos de usuário teve início na década de 1980 com a proposta de perceber a informação "[...] como uma construção social, criada pela interação de indivíduos e mensagens, dentro de contextos organizacionais e sociais diversos" (TIRATEL, 2000, p.07, tradução nossa). Este novo olhar sobre o comportamento de busca e necessidade de informação considera os estados cognitivos, afetivos e fisiológicos que apresenta o sujeito em um dado momento; a função que exerce no trabalho e na vida social; e o ambiente em que se encontra (WILSON, 1999).

Dervin; Nilan (1986, p.15) apontam que os estudos de abordagem tradicional tinham como foco o comportamento externo e não a cognição interna do sujeito. Com a inserção da abordagem alternativa passou-se a dar mais atenção e a utilizar elementos das ciências que tratam do comportamento humano e do desenvolvimento cognitivo, aspectos que podem trazer contribuições importantes para a área de Ciência da Informação.

A este respeito, Choo (2003, p.70) esclarece que:

[...] enquanto a pesquisa orientada para sistemas observa 0 que acontece no ambiente externo para o indivíduo em termos 
de instrumentos, serviços e práticas, a pesquisa orientada para o usuário examina as preferências e necessidades cognitivas e psicológicas do indivíduo, e como elas afetam a busca e os padrões de comunicação da informação.

Para Ferreira (1995) os estudos inseridos dentro da abordagem alternativa ou abordagem cognitiva focam os aspectos cognitivos e afetivos que interferem na busca e uso da informação; valorizam as experiências individuais; consideram o usuário como ser eminentemente ativo e criativo; e entendem que a necessidade da informação deve ser situacional e contextualizada. Na concepção da referida autora, estas características devem servir para a configuração dos novos sistemas de informação e de seus serviços que vão da aquisição, seleção e organização da coleção, passando pela recuperação da informação e a elaboração de programas de educação de usuários (FERREIRA, 1995).

A abordagem alternativa acentua a individualidade do sujeito que vive a realidade específica de cada sistema de informação, tal como esclarecem Nassif; Venâncio; Henrique (2007):

[...] ainda que os usuários da informação experienciem relações e interações sociais, eles vivem, ao mesmo tempo, experiências individuais. Isso significa que mesmo participando de domínios de ação que influenciem o seu comportamento, há condutas que são exclusivas de cada sujeito que devem também ser consideradas.

Sob esta perspectiva, os estudos empreendidos nessa abordagem consideram a cognição individual a partir do meio social em que os processos mentais de conhecimento do sujeito estão relacionados. Por esta razão, torna-se relevante pensar o comportamento informacional de um ponto de vista que seja possível analisar as condutas dos usuários em uma dada situação, isto é, evidenciar o arcabouço sociocultural de cada sujeito, incluindo habilidades intelectuais e todas as funções inerentes à cognição (processos de internalização e externalização, que engendram a consciência).

O usuário realiza diversas tarefas cognitivas na trajetória de busca e recuperação da informação, as quais variam de acordo com a estrutura cognitiva, interesses, necessidades, conhecimentos prévios e condições internas e externas. Dentre as variáveis intervenientes (WILSON, 1999) que podem influenciar o comportamento informacional dos sujeitos participantes, Calva González (2004) esclarece que os fatores internos são os aspectos afetivos, habilidades no uso de ferramentas de busca ou recursos informacionais, conhecimento prévio do assunto, idioma; já os fatores externos são, basicamente, o lugar onde o sujeito reside, o contexto em que a informação é acessada, os tipos de fontes de informação utilizadas e os aspectos de acessibilidade da informação 
disponíveis. Cabe destacar que, nesta pesquisa, tais variáveis não são exploradas tendo como base um dentre os vários modelos de comportamento informacional presentes na literatura da área (FISHER; ERDELEZ; MAcKECHINIE, 2006), uma vez que a intenção é identificar as estratégias metacognitivas tomando como referência os protocolos verbais dos próprios sujeitos investigados.

Para Varela; Barbosa (2012) a trajetória de busca e recuperação da informação é resultante de um ato de reflexão que inclui habilidades cognitivas de seleção, análise, síntese, comparação, organização e escrita, em que o sujeito relaciona e interpreta a informação para a construção de conhecimento e significado. Portanto, no processo de busca por informação são acionados diversos recursos cognitivos na mente do usuário para enfrentar as diferentes situações que Ihes são apresentadas; o que requer uma atitude crítica, analítica e reflexiva, aspectos indispensáveis para a geração de conhecimento.

O cenário ratificado potencializa a necessidade de se investigar o usuário de informação como sujeito metacognitivo, capaz não apenas de pensar, mas, sobretudo, de gerir seus processos cognitivos. Entende-se que este olhar mais verticalizado em torno do usuário e sua consciência sobre o seu comportamento ou, em outras palavras, controle consciente e ativo de seu próprio comportamento mediante determinado processo cognitivo pode propiciar uma melhor compreensão dos passos empreendidos pelo sujeito na busca pela informação em sistemas de recuperação da informação.

\section{Metacognição}

A mente humana é um processador de informações ao receber, armazenar, recuperar e transformar a informação; razão pela qual consegue transmitir a informação e ser estudada como um padrão e manipulação de padrões.

No âmbito da psicologia de processamento da informação o tripé estabelecido para classificar o conhecimento humano é composto pelo conhecimento procedimental, conhecimento declarativo e conhecimento metacognitivo (NEVES, 2007). O conhecimento procedimental - "como sabemos/conhecemos" visa compreender como os sujeitos utilizam a informação, ou seja, quais procedimentos são utilizados para alcançar os conhecimentos e recuperá-los no momento da necessidade de seu uso. Este conhecimento está acumulado na "memória em curto prazo" trabalhando, para tanto, com os dois tipos de procedimentos: os heurísticos e os algoritmos a fim de assegurar a eficácia e o objetivo pretendido e, também, com um conjunto de regras que garanta a obtenção deste objetivo. O conhecimento declarativo ou conhecimento representacional - "que sabemos" refere-se à compreensão sobre as coisas, do mundo em que vivemos e daquilo que fazemos para obter em nossa mente uma representação da informação que permita-nos em um momento posterior compreendê-la, armazená-la e utilizá-la. Este 
conhecimento encontra-se na chamada "memória a longo prazo" em forma de "esquemas mentais"1. Por sua vez, o conhecimento metacognitivo - consiste na "consciência sobre nosso próprio processo de pensar".

Flavell (1979, p.906) introduz o termo metacognição e o define como sendo "o conhecimento e cognição sobre um fenômeno cognitivo". Neste sentido, a metacognição é a "gestão dos processos cognitivos" pelo sujeito, isto é, "[...] o gerenciamento consciente sobre um fenômeno cognitivo" (NEVES, 2007, p.03). Estuda, portanto, o conhecimento que o sujeito possui de si mesmo e dos seus sistemas de pensamento ou "pensamento sobre o pensamento" (FLAVELL, 1979; LIVINGSTON, 1997). Logo, o conhecimento metacognitivo emerge da reflexão dos processos cognitivos (LAWSON, 1984),

Ainda para Flavell (1979) os sujeitos que monitoram seu próprio desempenho para a realização de uma determinada tarefa assimilam de forma mais eficaz as informações recebidas e, como resultado, executam as tarefas com mais habilidade na medida em que aplicam as técnicas que possuem para resolver o problema. Sobre isto, Figueira (2003) esclarece que para dirigir e regular a sua própria cognição, o sujeito deve conhecer a si próprio como processador de informação, ou seja, ter consciência das suas características.

O monitoramento dos empreendimentos cognitivos ocorre por meio da interação de "conhecimento metacognitivo" e "experiências metacognitivas" (FLAVELL, 1979). Ribeiro (2003) esclarece que o conhecimento metacognitivo possui três variáveis: pessoa - refere-se ao conhecimento que o sujeito adquiriu sobre si próprio, relativamente à condição humana, a habilidade e motivação do outro e a habilidade e motivação própria; tarefa - o sujeito possui conhecimento sobre a natureza, tipo de processamento e gerenciamento necessário para o sucesso na execução da tarefa e; estratégia - conhecimento sobre as habilidades utilizadas na obtenção dos objetivos nos diferentes tipos de processos cognitivos, ou seja, refere-se ao conhecimento sobre os meios, processos ou ações a serem tomadas para atingir com maior eficácia os objetivos numa determinada tarefa.

Quanto às experiências metacognitivas, Neves (2004) afirma que estas ocorrem em situações de pensamento altamente consciente, cujos produtos dessa experiência podem conduzir o sujeito aos seguintes desdobramentos: a) estabelecer novas metas e revisar ou abandonar outras; b) afetar a sua base do conhecimento metacognitivo pela adição, apagamento ou revisão de uma determinada ação; c) observar o relacionamento entre metas, meios e experiências metacognitivas com o resultado obtido em uma dada situação, assimilando o que foi observado ao conhecimento metacognitivo anterior; d) ativar estratégias direcionadas às metas cognitivas - evocadas para fazer progresso

\footnotetext{
${ }^{1}$ Esquemas mentais são "estruturas cognitivas relacionadas a um conjunto de conhecimentos armazenados em sequência temporal ou causal, em que são mantidos os conjuntos de características dos objetos e seres que nos rodeiam, onde tal modelo mental é aprendido a partir da vivência do indivíduo em sociedade" (NEVES, 2006, p.41).
} 
cognitivo; e e) fazer uso de metas metacognitivas para monitorar o progresso (NEVES, 2006). Cabe destacar que as estratégias metacognitivas não são fixas, variam de acordo com cada sujeito. Ademais, por ser uma ação gerenciada, a metacognição permite ao sujeito selecionar, criar, analisar, mudar e redirecionar sua praxe cognitiva, conduzindo-o a uma variedade de experiências, metas e estratégias metacognitivas (BARROS; NEVES, 2011).

No âmbito da Ciência da Informação, a metacognição é foco investigativo de diversos estudos. Na Arquivística, a temática foi explorada por Barros; Neves (2011) que, tomando como base o modelo de comportamento de busca de informação de David Ellis (1989), analisaram se as estratégias metacognitivas do profissional da informação de arquivo se assemelham ou se diferenciam das traçadas por pesquisadores no comportamento de busca da informação. No universo biblioteconômico, muitos são os estudos sobre metacognição cuja investigação versa para a prática do indexador na condição de leitor profissional. Especificamente no contexto da metodologia qualitativocognitivo com o uso do protocolo verbal, destacam-se os trabalhos de Fujita (1999) que investigou os procedimentos de leitura documental em condições específicas e concluiu que os indexadores utilizam estratégias metacognitivas de leitura; Neves (2004) que demonstrou a necessidade de reestruturação na formação do bibliotecário, em busca de métodos em que a metacognição seja usada como estratégia de leitura; e Neves; Dias; Pinheiro (2006) que identificaram semelhanças e divergências no uso de determinadas estratégias metacognitivas entre leitores proficientes indexadores e não indexadores, cujos resultados indicam a necessidade de se introduzir formalmente o ensino de estratégias metacognitivas no treinamento de leitura do indexador. De modo geral, estes estudos buscam analisar de que modo os processos cognitivos e metacognitivos do profissional indexador contribuem para a leitura documental e, também, para a qualidade da indexação.

No entanto, não consta na área estudos que abordem a metacognição de usuários e sua influência no comportamento de busca da informação em contexto de bibliotecas universitárias. Tal lacuna merece uma observação ampla e cuidadosa, uma vez que na contemporaneidade os produtos e serviços informacionais de domínios específicos devem corresponder às expectativas da demanda, propiciando facilidade, rapidez e qualidade na recuperação e uso em diversos setores da sociedade. Consequentemente, todos os fatores intervenientes e que possam clarificar o processo de busca da informação mostram-se relevantes e de fundamental importância para o campo científico da Ciência da Informação.

\section{Procedimentos metodológicos}

A configuração desta pesquisa de natureza qualitativa está fundamentada numa abordagem sóciocognitiva, sendo norteada pelos 
estudos de usuários de abordagem alternativa em Ciência da Informação. As coletas de dados foram realizadas na biblioteca universitária da Universidade Estadual Paulista - UNESP, Campus de Marília com aplicação da técnica de Protocolo Verbal com três discentes de graduação em Fonoaudiologia, cursando o último ano do curso supracitado. O critério adotado para a seleção dos participantes deu-se por entender que os mesmos estariam familiarizados com o processo de busca da informação em virtude da formação eminente, característica que os potencializam como usuários proficientes no uso do catálogo online.

De modo geral, o Protocolo Verbal ou registro de relatos verbais é uma técnica de coleta de dados introspectiva que:

[...] propõe o acesso ao processo de pensamento do indivíduo que executa determinada atividade com objetivo prédeterminado. Enquanto executa a tarefa, o indivíduo verbaliza 'tudo o que Ihe passa pela cabeça' e, após a transcrição de seu Protocolo Verbal, é possível observar os conhecimentos declarativo, procedimental e metacognitivo sobre a atividade realizada (FUJITA; RUBI, 2007, p.143).

Na técnica do protocolo verbal o pesquisador analisa todo o processo de verbalização do sujeito participante enquanto realiza determinada atividade, exercendo o mínimo de intervenção e/ou interação. Essa exteriorização é gravada e transcrita literalmente, produzindo protocolos verbais. De modo geral, protocolos são definidos como relatos verbais dos processos mentais conscientes dos informantes (CAVALCANTI, 1989). A modalidade de aplicação do protocolo verbal foi a individual com intervenção moderada das pesquisadoras, a qual possibilita a obtenção de relatos individuais da própria cognição dos sujeitos participantes durante a execução de uma tarefa ou à medida que esteja sendo relembrada para a resolução de problemas e tomada de decisões (ERICSSON; SIMON 1984).

Esclarece-se que o método em questão foi sistematizado de acordo com o perfil e objetivos da presente pesquisa, cujo delineamento é quase experimental. Desse modo, foi requerido aos sujeitos participantes que realizassem o processo de busca e recuperação da informação conforme estavam habituados, os quais foram instruídos individualmente sobre o procedimento de "pensar alto" (Think aloud). Para tanto, foi solicitado que os mesmos explicitassem, do modo mais claro possível, o que se passava em suas mentes durante a atividade, isto é, que expressassem verbalmente todo e qualquer pensamento no decorrer da atividade de recuperação da informação, inclusive dúvidas e possíveis soluções vislumbradas.

Para a realização da atividade proposta utilizou-se a interface de busca simples do Catálogo Athena - banco de dados bibliográficos da UNESP. Esclarece-se que os campos para as pesquisas (autor, título, assunto, etc) foram escolhidos pelos próprios sujeitos participantes e de acordo com seus interesses. Sendo assim, foi possível observar a autorregulação e estratégias metacognitivas dos usuários durante os 
procedimentos realizados para a recuperação da informação nos "campos para busca" disponibilizados pela interface do referido catálogo online.

Primeiramente, o "pensar alto" dos sujeitos participantes durante a realização de toda tarefa foi gravado. O tempo dedicado a cada uma das sessões de coleta de dados com uso da técnica de Protocolo Verbal Individual variou entre cinco e dez minutos, dependendo do grau de complexidade de cada pesquisa. Procedeu-se, no segundo momento da pesquisa, a transcrição literal dos comentários e verbalizações realizadas pelos participantes, as quais requerem o uso de nomenclaturas para a identificação das falas de cada sujeito, utilizadas nesta pesquisa da seguinte forma: $(\mathrm{SG} 1)=$ sujeito de graduação $1 ;(\mathrm{SG} 2)=$ sujeito de graduação 2; (SM3) = sujeito de graduação 3. As transcrições dos protocolos verbais, atreladas ao referencial teórico explorado e ao objetivo da pesquisa subsidiaram as quatro categorias que permitiram analisar os dados coletados, identificando os principais fenômenos e aspectos significativos para a observação das estratégias metacognitivas dos usuários no processo de busca da informação, sendo estas: 1) conhecimento especializado; 2) avaliação do próprio conhecimento; 3) regulação; e 4) organização dos processos cognitivos.

\section{Resultados e discussão}

A trajetória metacognitiva dos sujeitos participantes, individualmente e combinadas entre si, empregadas durante o processo de busca e recuperação da informação no catálogo online são dispostas nas categorias de análise que contextualizam e identificam os resultados obtidos por meio das transcrições dos protocolos verbais. As categorias de análise tomam como referência as definições abaixo, sendo elaboradas tendo em vista sua adequação ao procedimento da pesquisa, conforme segue:

Conhecimento especializado - o sujeito parte do conhecido e visualiza as possíveis possibilidades no contexto em que cada passo está sendo dado;

Regulação - o sujeito cria conceitos ou atributos que norteiam a tomada de decisão em seguir ou escolher um dado caminho, o qual pode ser confirmado em sua totalidade ou descartado, fazendo-se necessário reformular ou elaborar novas orientações;

Avaliação do próprio conhecimento - ocorre quando o sujeito questiona a si mesmo sobre um esclarecimento necessário para a compreensão da tarefa, visando se aproximar do objetivo esperado; e

Organização dos processos cognitivos - o sujeito evoca na memória informações que sedimente a tarefa, relembrando passos ou roteiros acionados em situações anteriores. 
Concernente à elaboração de compreensão monitorada,
focalizada no contexto da categoria "conhecimento
especializado", nota-se que o processo de busca da
informação é um comportamento habitual dos sujeitos
participantes, em virtude da facilidade de realizarem os
procedimentos necessários a serem empregados para
encontrar, recuperar e acessar a informação desejada.

Vou realizar a busca pelo autor, pois o sistema me dá várias obras desse autor e aí eu consigo recuperar o documento que eu preciso. Acho mais fácil assim... (SG1).

Eu utilizo o catálogo da biblioteca sempre que eu preciso realizar uma pesquisa porque eu já conheço o sistema /.../ bom, então vejamos, eu entro por aqui e coloco o assunto /.../ daí eu escolho dentro dessas opções a que melhor condiz com o que eu trabalho na minha pesquisa. Tá vendo, eu recupero outros documentos e consigo melhorar a minha pesquisa, daí eu filtro aquilo que eu quero (SG2).

Nossa, eu achei que pelo título eu conseguiria recuperar mais coisas /.../ bom, então eu vou retomar a busca pelo assunto para ver se aparecem obras mais relevantes /.../ oh, tá vendo, eu já encontrei o que eu procurava indo desse jeito e consigo encontrar outras coisas que tem a ver com a pesquisa. Deixe-me ver esse aqui /.../ bem melhor que do outro jeito (SG3).

Verifica-se a capacidade dos sujeitos participantes em gerir a pesquisa no sistema de informação na medida em que conseguem compreender e explicitar as relações entre os procedimentos, objetivo e desempenho pretendido. Isso demonstra, dentre outros fatores, que os sujeitos conseguem guiar, avaliar, corrigir e regular o processo de busca e recuperação da informação no catálogo online, em direção à informação pretendida. Tal comportamento vai ao encontro com a afirmação de Figueira (2003, p.8) ao expor que a metacognição permite "[...] aos sujeitos tomarem consciência dos processos adotados, selecionarem as estratégias mais adequadas à realização da tarefa e [monitorarem] a aplicação destas aos objetivos que pretendem atingir". Nesse sentido, o esforço consciente empreendido por cada sujeito na recuperação da informação demonstra um comportamento de busca da informação capaz de satisfazer suas necessidades particulares, como resposta a uma lacuna em seus conhecimentos.

Quanto à categoria "regulação", observa-se que os sujeitos com competências metacognitivas bem desenvolvidas compreendem os objetivos da tarefa, planificam a sua execução, são capazes de aplicar e alterar de forma consciente as estratégias a serem executadas, bem como avaliar o seu próprio processo de execução, visando se aproximar do objetivo esperado. Portanto, o processo de busca da informação se apresenta como uma tarefa em que existe um objetivo a ser atingido, mas diante da qual se conta com procedimentos conhecidos pelos sujeitos, capazes de conduzi-los à solução do problema, conforme declarações abaixo: 
Acredito que seja melhor eu buscar por autor /.../ eu já tenho noção do documento que eu preciso e já busco direto, porque se eu, por exemplo, for colocar o assunto ou título do documento o sistema vai me trazer muita coisa. Não dá para procurar por um tema muito geral que aí vem um monte de coisa /.../ aí, não falei, já achei o livro que eu queria (SG3).

Recorrendo à literatura acerca dessa ocorrência, tem-se que a prática da metacognição conduz o sujeito a uma melhora de sua atividade intelectual, sendo considerado um contributo ao processo de aprendizagem (FIGUEIRA, 2003). No que tange ao processo de busca da informação, a metacognição oferece aos usuários a possibilidade de regularem suas ações de forma consciente perante as possíveis barreiras que podem surgir na execução da tarefa, tornando-os capazes de reformularem ou elaborarem novas orientações com fins de satisfazer suas necessidades de informação.

A análise da categoria "avaliação do próprio conhecimento" demonstrou que os sujeitos participantes questionam a si próprios quanto às dúvidas sobrepostas durante a realização da tarefa. Os sujeitos creditam aos conhecimentos prévios uma possível solução e esclarecimento necessário para se aproximarem do objetivo pretendido.

Nossa, eu tinha certeza de que eu encontraria esse livro buscando por autor, mas não encontrei. Vou voltar à página principal e realizar a busca agora por assunto pra ver se dá certo... (SG1).

Nossa, será que eu fiz algo errado, porque não recuperou. Acho que do outro jeito é melhor (SG2).

Será que se eu colocar alguma informação aqui nesse campo eu vou conseguir refinar a busca, porque eu não me lembro de ter feito isso das outras vezes (SG3).

Fica claro, portanto, que a utilização de estratégias metacognitivas propicia ao sujeito conhecer seus próprios modos de pensar e, consequentemente, inferir com ações positivas para a resolução de problemas. Esta ideia vai ao encontro com a proposta da presente pesquisa e confirma que o conhecimento da metacognição de usuários é de grande valia para se compreender, com maior propriedade, as ações e possíveis barreiras enfrentadas pelos usuários no processo de busca e recuperação da informação em sistemas de informação.

$\mathrm{Na}$ categoria "organização dos processos cognitivos", observa-se que no decorrer da atividade foram retomadas situações vivenciadas pelos sujeitos em outras pesquisas realizadas no catálogo online para prosseguirem com a busca atual. Isto é verificado com as falas que expõem situações anteriores e as ações positivas empreendidas nestas ocasiões. 
Da outra vez que eu fiz a busca no sistema não encontrei muita coisa. Então eu vou escolher esse campo aqui (autor) porque de outro modo eu não consigo encontrar o livro que eu procuro tão fácil /.../ aparecem muitas obras que não tem nada a ver com o tema que eu coloco (SG1).

Para essa pesquisa eu vou utilizar o campo de busca por assunto porque eu já estou acostumado por aqui /.../ Eu prefiro dessa maneira porque o meu tema de pesquisa é pouco trabalhado na área e procurando desse jeito eu tenho a chance de conseguir mais resultados (SG2).

Eu lembro que da última vez que eu usei o sistema não consegui encontrar muita coisa relevante para a minha pesquisa fazendo a busca por autor. Então eu agora costumo fazer a busca por assunto /.../ vai que a biblioteca comprou novos materiais e daí fica mais fácil eu recuperar coisas novas (SG3).

A evocação na memória por buscas anteriores no sistema de informação para a condução eficaz da tarefa atual aponta, sobretudo, a capacidade do sujeito em aprender com as experiências anteriores (LEFFA, 1996). Nesse sentido, os sujeitos participantes fazem uso de ações empreendidas em outras ocasiões no intuito de identificar como resolver situações inesperadas ou traçar os passos a serem realizados para recuperar a informação desejada. Essa postura está em consonância com o pensamento apresentado por Davis; Nunes; Nunes (2005, p.211212) o qual estabelece que, "[...] ao fazer uso da metacognição, o usuário torna-se um espectador de seus próprios modos de pensar e das estratégias que emprega para resolver problemas, buscando identificar como aprimorá-los".

De modo geral, a análise dos dados demonstra que as principais estratégias metacognitivas identificadas nos sujeitos participantes foram: a capacidade de gerir os processos de pensamento; e a capacidade de descrever e tomar consciência dos seus próprios pensamentos, presentes aqui a autorregulação ${ }^{2}$ e o autocontrole do processo de busca da informação e das ações a serem empreendidas para o alcance do objetivo pretendido. Mediante a isso, vale inferir que as estratégias metacognitivas são mais importantes que as cognitivas no processo de busca da informação, pois as mesmas podem ser ensinadas/aprendidas, a experiência pode melhorá-las (LEFFA, 1996). Consequentemente, quanto maior a familiaridade com a interface do sistema, melhor capacitado o

\footnotetext{
${ }^{2}$ A autorregulação surge quando o sujeito aprende a perseguir seus objetivos, age com motivação intrínseca, prioriza a meta, planeja, decide, age com autonomia, avalia as situações que lhe são apresentadas, antecipa situações e implicações (BORUCHOVITCH; BZUNECK, 2004).
} 
sujeito estará para a realização do processo de busca e recuperação da informação com a obtenção de resultados desejáveis.

Por fim, a análise dos resultados confirma preliminarmente que: a) o conhecimento de estratégias metacognitivas repercute na qualidade dos resultados obtidos no processo de busca da informação; b) as experiências metacognitivas interferem no modo como se concretiza o processo de busca da informação em catálogos coletivos online de bibliotecas universitárias; e c) tem-se a necessidade do encaminhamento de estudos complementares que visem avançar na compreensão das estratégias metacognitivas dos usuários no processo de busca da informação.

\section{Considerações finais}

Pesquisas sobre a temática de comportamento informacional são um meio eficaz de se investigar o usuário no processo de busca, recuperação e uso da informação nos diferentes sistemas de informação. Em razão disso, o intento desta pesquisa foi ampliar o universo investigativo da abordagem alternativa em Ciência da Informação que norteia os estudos de comportamento informacional, a fim de observar a trajetória metacognitiva de sujeitos proficientes no processo de busca da informação em catálogo coletivo online. Portanto, buscou-se identificar as estratégias metacognitivas empreendidas para a recuperação da informação desejada e, paralelamente, obter subsídios que contribuam para que produtos e serviços de informação sejam moldados de acordo com as preferências e características dos usuários.

Tomando como base os resultados obtidos, pode-se inferir que a metacognição do usuário é um importante campo a ser acionado nos discursos em Ciência da Informação, especificamente no que tange aos estudos destinados à representação e organização da informação. Isto porque, ao passo que se obtém o entendimento das práticas cognitivas e das capacidades metacognitivas de usuários na busca e recuperação da informação em domínios específicos, como é o caso da biblioteca universitária, seus produtos e serviços tendem a ser cada vez mais compatíveis com as necessidades informacionais de sua comunidade. Portanto, cabe a Ciência da Informação avançar em pesquisas que cerquem o usuário e todos os fatores interferentes que causam barreiras no uso de produtos e serviços de informação nos mais variados contextos socioculturais em que a informação se apresente.

Dessa forma, recomenda-se que pesquisas posteriores explorem a metacognição de usuários à luz dos vários modelos de comportamento informacional e comportamento de busca apresentados à área de Ciência da Informação, os quais, atrelados aos demais fatores envolvidos na forma dos sujeitos lidarem com a informação, podem contribuir significativamente para ampliar a identificação de estratégias metacognitivas que cercam o processo de busca da informação realizado pelo usuário em diferentes domínios informacionais. Como consequência, 
poder-se-á obter um conjunto de habilidades que tenham maior possibilidade de sucesso no processo de busca da informação; ensinar ao usuário de informação estratégias para a solução de problemas passíveis de autorregulação; e propiciar ao usuário de informação autonomia na gestão das tarefas e aprendizagens nos mais variados sistemas de informação.

\section{Referências}

BARRETO, A. A. Padrões de assimilação da informação... In: RODRIGUES, G. M.; LOPES, I. L. Organização e Representação do conhecimento na perspectiva da Ciência da Informação. Brasília: Thesaurus, 2003.

BARRETT, A. The Information-Seeking Habits of Graduate Student Researchers in the Humanities. Journal of Academic Librarianship, v. 31, n. 4, p. 324-331, jul. 2005.

BARROS, D. S.; NEVES, D. A. de B. Estudo de usuários no Arquivo Público do Estado do Maranhão (APEM): analisando as estratégias metacognitivas no processo de busca de informação. Perspectivas em Ciência da Informação, v.16, n.4, p.228-242, out./dez. 2011.

BATES, M. J. Learning about the information seeking of interdisciplinary scholars and students. Library Trends, v. 45, n. 2, p. 155-64, Fall 1996.

BORUCHOVITCH, E.; BZUNECK, J. A. (org). Aprendizagem: processos psicológicos e o contexto social na escola. Petrópolis: Vozes, 2004.

CALVA GONZÁLES, J. J. Las necesidades de información: fundamentos teóricos y métodos. México: Universidad Nacional Autónoma de México, 2004. 285 p.

DAVIS, C.; NUNES, M. R. M.; NUNES, C. A. A. Metacognição e sucesso escolar: articulando teoria e prática. Cadernos de Pesquisa, v. 35, n. 125, maio/ago. 2005.

DERVIN, B; NILAN, M. Information needs and uses. Annual Review of Information Science and Technology, v. 21, p. 3-33, 1986.

ELLIS, David. A behavioural approach to information retrieval system design. Journal of Documentation, London, v. 45, n. 3, p. 171-212, sep. 1989.

ERICSSON, K. A.; SIMON, H. A. Protocol analysis: verbal reports as data. Cambridge: MIT Press, 1984.

FIGUEIRA, A. P. C. Metacognição e seus contornos. Revista Iberoamericana de Educación, OEI, pp. 1-20, 2003. Disponível em: <http://www.rieoei.org/deloslectores/446Couceiro.pdf>. Acesso em: 17 de setembro de 2012 .

FISHER, K. E.; ERDELEZ, S.; MACKECHNIE, L. Theories of information behavior. Medford: Information today, 2006. (ASIST Monograph series) 
FLAVELL, J. H. Metacognition and cognitive monitoring: a new area of cognitive-developmental inquiry. American Psychologist, v. 34, 906-911, 1979.

FUJITA, M. S. L. ; AGUSTIN LACRUZ, M. Del C. ; GÓMEZ DIAZ, R. La indización y catalogación de materias en entornos bibliotecarios: desafíos y perspectivas. In: CONGRESO DEL CAPÍTULO ESPAÑOL DE ISKO, 10., 2011, Ferrol. Actas... Ferrol: Universidade da Coruña, 2011. p. 1-13.

FUJITA, M. S. L. A leitura do indexador: estudo de observação.

Perspectivas em Ciência da Informação, v. 4, n.1, p.101-116, jan./jun. 1999.

LAWSON, M. J. Being executive about metacognition. In J. R. Kirby (Ed.), Cognitive strategies and educational performance. New York: Academic Press, 1984, p.89-109.

LE COADIC, Y-F. A ciência da informação. Brasília: Briquet de Lemos/Livros. 1996.

LEFFA, V.J. Aspectos da Leitura. Porto Alegre: Sagra, 1996. 105 p.

LIVINGSTON, J. A. A. Metacognition: an overview. Copyright, 1997.

Disponível em: <http://gse.buffalo.edu/fas/shuell/cep564/Metacog.htm>. Acesso em: 21 de agosto de 2012.

LOPES, I. L. Estratégia de busca na recuperação da informação: revisão de literatura. Ciência da Informação, v.31, n.2, p.60-71, 2002.

NASSIF, M. E.; VENÂNCIO, L. S.; HENRIQUE, L. C. J. Sujeito, contexto e tarefa na busca de informação: uma análise sob a ótica da cognição situada. DataGramaZero: Revista de Ciência da Informação, v.8 n.5, 2007. Disponível em:

<http://www.datagramazero.org.br/out07/Art 04.htm >. Acesso em: 19 de maio de 2012.

NEVES, D. A. de B. Aspectos metacognitivos na leitura do indexador. 2004. Tese (Doutorado em Ciência da Informação) - Universidade Federal de Minas Gerais, Belo Horizonte, 2004.

NEVES, D. A. de B.; DIAS, E. W.; PINHEIRO, A. M. V. Uso de estratégias metacognitivas na leitura do indexador. Ciência da Informação, Brasília, v. 35, n. 3, p. 141-152, set./dez. 2006.

NEVES, D. A. B. Leitura e metacognição: uma experiência em sala de aula. Enc. Bibli: R. Eletr. Bibliotecon. Ci. Inf., Florianópolis, n. 24, p. 1-9, 20 sem. 2007.

RIBEIRO, C. Metacognição: Um apoio ao processo de aprendizagem. Psicologia: Reflexão e Crítica, vol. 16, n. 1, p. 109-116. 2003.

ROWLEY, J. A biblioteca eletrônica. Brasília: Briquet de Lemos, 2002.

TIRATEL, S. R. de. Accessing Information use by humanists and social scientists: a study at the Universidad de Buenos Aires, Argentina. The journal of Academic Librarianship, v. 26, n. 5, p. 346-354, Set. 2000. 
VARELA, A.; BARBOSA, M. L. A. Trajetórias cognitivas subjacentes ao processo de busca e uso da informação: fundamentos e transversalidades. Encontros Bibli: revista eletrônica de biblioteconomia e ciência da informação, v. 17, n. esp.1, p.142-168, 2012.

WILSON, T. D. Models in information Behavior research. Journal of Documentation, v. 55, n. 3, p. 249-270, 1999. 